\title{
Programmed cell death in the unicellular protozoan parasite Leishmania
}

\author{
N Lee ${ }^{1}$, S Bertholet ${ }^{2}$, A Debrabant ${ }^{1}$, J Muller $^{3}$, R Duncan $^{1}$ and \\ HL Nakhasi ${ }^{\star, 1}$ \\ 1 Division of Emerging and Transfusion Transmitted Diseases, OBRR, CBER, \\ FDA, Bethesda, MD 20892, USA \\ 2 Laboratory of Parasitic Biology and Biochemistry, Division of Bacterial, \\ Parasitic and Allergenic Products, OVRR, CBER, FDA, Bethesda, MD 20892, \\ USA \\ ${ }^{3}$ Laboratory of Vector Borne Viral Diseases, Division of Viral Products, OVRR, \\ CBER, FDA, Bethesda, MD 20892, USA \\ * Corresponding author: HL Nakhasi, LBPUA, DETTD, OBRR, CBER, FDA, BIdg. \\ 29 Rm. 222, 8800 Rockville Pike, Bethesda, MD 20892, USA. \\ Tel: (301) 496-2205; Fax: (301) 480-7928; E-mail: Nakhasi@cber.fda.gov
}

Received 2.5.01; revised 23.7.01; accepted 31.8.01

Edited by G Melino

\begin{abstract}
In the present study we have demonstrated some features characterizing programmed cell death (PCD) in the unicellular protozoan parasite Leishmania donovani, the causative agent of visceral Leishmaniasis. We report that PCD is initiated in stationary phase cultures of promastigotes and both in actively growing cultures of axenic amastigotes and promastigotes upon treatment with anti Leishmanial drugs (Pentostam and amphotericin B). However, the two cell types respond to antileishmanial drugs differently. The features of PCD in $L$. donovani promastigotes are nuclear condensation, nicked DNA in the nucleus, DNA ladder formation, increase in plasma membrane permeability, decrease in the mitochondrial membrane potential $\left(\Delta \Psi_{\mathrm{m}}\right)$ and induction of a PhiPhiLux (PPL)-cleavage activity. $P C D$ in both stationary phase culture and upon induction by amphotericin $B$ resulted first in the decrease of mitochondrial membrane potential followed by simultaneous change in plasma membrane permeability and induction of PPL-cleavage activity. Of the total PPL-cleavage activity, several caspase inhibitors inhibited a significant amount (21-34\%). Inhibitors of cathepsin or calpain did not inhibit PPL-cleavage activity. Taken together this study demonstrates that the characteristic features of PCD exist in unicellularprotozoan Leishmania donovani. The implication of PCD on the Leishmania pathogenesis is discussed. Cell Death and Differentiation(2002) 9,53-64. DOI: 10.1038/sj/cdd/4400952
\end{abstract}

Keywords: programmed cell death; Leishmania; promastigote; amastigote; Pentostam; amphotericin B

Abbreviations: PCD, programmed cell death; TMRE, tetramethylrhodamine ethyl ester; CCCP, carbonyl cyanide p-trifluoromethoxyphenylhydrazone; TUNEL, terminal deoxy uridine triphosphate nick end labeling; PPL, PhiPhiLux; $\Delta \Psi_{\mathrm{m}}$, mitochondrial membrane potential

\section{Introduction}

Leishmania, a unicellular Trypanosomatid protozoan parasite causes a wide range of human diseases ranging from the localized self-healing cutaneous lesions to fatal visceral infections. Leishmania have a digenic life cycle, which is characterized by the presence of a flagellated promastigote form in the sand fly vector and a nonmotile amastigote stage within phagolysomes of mammalian macrophages. ${ }^{1-3}$ The ability of this parasite to undergo differentiation from the promastigote to the amastigote form is crucial for its pathogenesis. ${ }^{4}$ Further, during its life cycle, Leishmania grows in diverse and hostile environmental conditions ${ }^{5}$ and has to control growth as well as preserve individuals that are fit to continue infectivity.

Programmed cell death (PCD) is an essential part of cell biology and is thought to have evolved not only to regulate growth and development in multicellular organisms ${ }^{6,7}$ but also to guard against viral infections ${ }^{8-10}$ and the emergence of cancer. ${ }^{11,12}$ However, recent studies, which showed the existence of PCD in unicellular organisms, have postulated a functional role of PCD in the biology of unicellular organisms. ${ }^{13-18}$ Further, in light of a recently reported nonapoptotic programmed cell death, parapoptosis, ${ }^{15,19}$ it is important to understand the type of PCD that exists in unicellular organisms. It has been postulated that in order to promote and maintain clonality within the population, the Trypanosomatids must have developed an altruistic mechanism to control growth. ${ }^{14}$ Recently, PCD has been shown to be involved in the control of cell proliferation of $T$. cruzi in vitro ${ }^{16}$ and in the insect vector mid gut. ${ }^{20}$ Features of PCD also have been observed in procyclic insect form of $T$. brucei rhodesiense upon treatment in vitro with lectin. ${ }^{17} \mathrm{Ca}^{2+}$ modulation by heat shock during differentiation in L. amazonnesis also induced PCD. ${ }^{18}$ A cell death process akin to PCD was also demonstrated to exist in Dictyostelium discoideum, an organism that exists both as a unicellular and multicellular form, ${ }^{15}$ thus reinforcing the idea that the pathway for PCD must have evolved before the evolution of multicellularity. ${ }^{15}$ All these observations point towards the existence of a PCD pathway in Trypanosomatids. Whether the type of PCD that exists in Trypanosomatids is the same as in multicellular organism remains to be seen.

In the present study we explored the existence of PCD in Leishmania donovani. We showed for the first time that the parasite death during stationary phase in culture and by various antileishmanial drugs involves PCD. In both of these cases, we demonstrated that PCD began with depolarization of mitochondrial membrane potential followed by induction of a caspase-like activity. Further, the induction of caspase-like activity is also observed in freshly isolated $L$. donovani from infected animals and in an another species of Leishmania. 


\section{Results}

Characteristic features of PCD in stationary phase cultures of promastigotes of Leishmania donovani

When promastigotes of $L$. donovani were cultured in vitro from a starting cell density of $1 \times 10^{6} / \mathrm{ml}$, there was an exponential increase in cell number in the first 3-4 days, followed by a plateau in growth (Figure 1A). The latter part of the growth curve was described as stationary phase since there was no substantial increase in cell number. We investigated the nature of cell death occurring in stationary phase culture, which could be the result of either necrosis or PCD. A characteristic feature of PCD in multicellular organisms is the formation of a DNA ladder. In stationary phase promastigotes, we observed a DNA fragmentation pattern in multiples of oligonucleosomal length units (Figure 1B). The intensity of the DNA ladder was more pronounced in the latter stages of stationary phase (lane D10). Transmission electron microscopy showed that promastigotes also undergo morphological changes characteristics of PCD at day 7 , which includes a certain degree of condensation of nuclear chromatin (Figure $2 \mathrm{~B}$ vs A). Further, by TUNEL assay, an indicator of DNA nicking, we observed a significant number of TUNEL positive cells in stationary phase cultures (Figure 2D). However, only a few TUNEL positive cells were observed in late logarithmic phase cultures of promastigotes (Figure 2C, white arrowhead). Thus, in vitro grown Leishmania donovani exhibit nuclear changes similar to those associated with PCD in higher eukaryotes.

\section{Decrease in mitochondrial membrane potential of Leishmania donovani promastigotes during stationary phase cultures}

A reduction in mitochondrial membrane potential $\left(\Delta \Psi_{\mathrm{m}}\right)$ has been observed in a number of models of apoptosis. ${ }^{21-26}$ However, it is not clear whether $\Delta \Psi_{\mathrm{m}}$ is the primary event in
PCD. ${ }^{27-32}$ Little is known about the involvement of mitochondria in PCD in unicellular organisms such as Leishmania. Tetramethylrhodamine ethyl ester (TMRE), is a cationic lipophilic dye that enters cells and reversibly accumulates in the negatively charged mitochondrial matrix depending on mitochondrial membrane potential according to the Nernst equation potential. ${ }^{33}$ Live cells that were either in late log phase or at different times in the stationary phase cultures were incubated with TMRE and fluorescence was measured by flow cytometry. To prove that Leishmania cells functionally respond to pharmacological alteration of $\Delta \Psi_{\mathrm{m}}$, TMRE-loaded promastigotes were treated with different concentrations of the protonophore carbonyl cyanide $p$ trifluoromethoxy-phenylhydrazone (CCCP), which has been shown to induce loss of mitochondrial membrane potential in various cell types. ${ }^{34,35}$ We first examined the effect of CCCP on promastigotes at day 3 of culture showing no hallmarks of PCD. Results show that addition of CCCP $(50 \mu \mathrm{M})$ resulted in maximal decrease of TMRE fluorescence indicating loss of mitochondrial membrane potential (Figure 3). We next assessed whether a change in mitochondrial membrane potential occurs in these cells during stationary phase culture. When promastigotes at day 6 of culture were loaded with TMRE, two populations of cells were observed (Figure 4B). One population representing $46.8 \%$ of cells (labeled M2, Figure 4B) had a mean TMRE fluorescence similar to day 3 cells (Figure 4A). The second population representing 53\% of cells (labeled M1, Figure 4B) had a substantial reduced mean TMRE fluorescence. By day 7 the low TMRE fluorescence M1 population increased to $77 \%$ of total cells and the high TMRE (M1) population decreased to $21.4 \%$ (Figure 4C). Treatment of cells with CCCP $(50 \mu \mathrm{M})$ showed that the high TMRE (M2) population responded to membrane potential changes whereas, the low TMRE (M1) population was insensitive (Figure 4D,E,F). These results suggest that, upon aging, Leishmania promastigotes loose mitochondrial membrane potential.

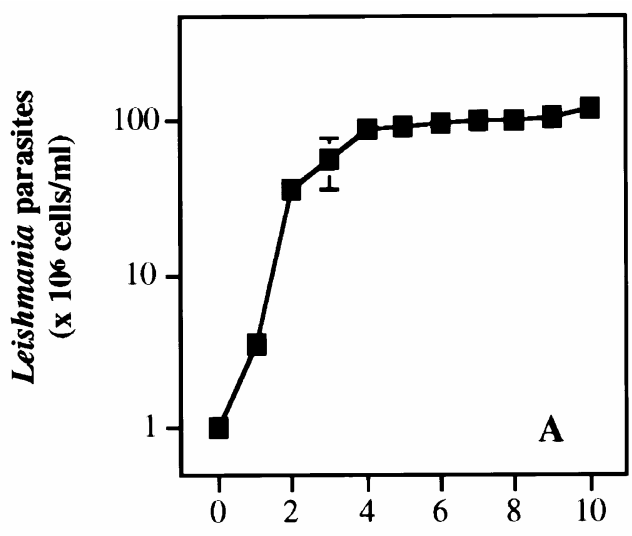

Days in culture

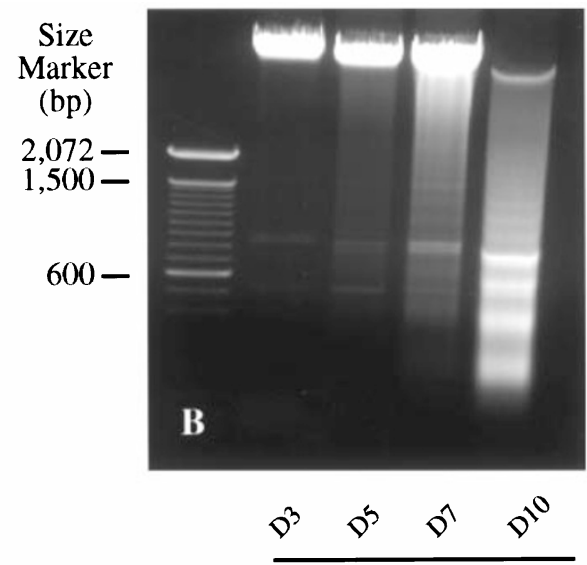

Days in culture

Figure 1 Cell growth in culture and the appearance of DNA ladder formation. L. donovani promastigotes were cultured in vitro at an initial concentration of $1 \times 10^{6}$ cells $/ \mathrm{ml}$. The cells were kept in culture for 10 days and counted at indicated days (A). DNA was isolated at each time point, run through an agarose gel, and visualized by ethidium bromide (B). DNA size markers are shown in base pairs (bp) 


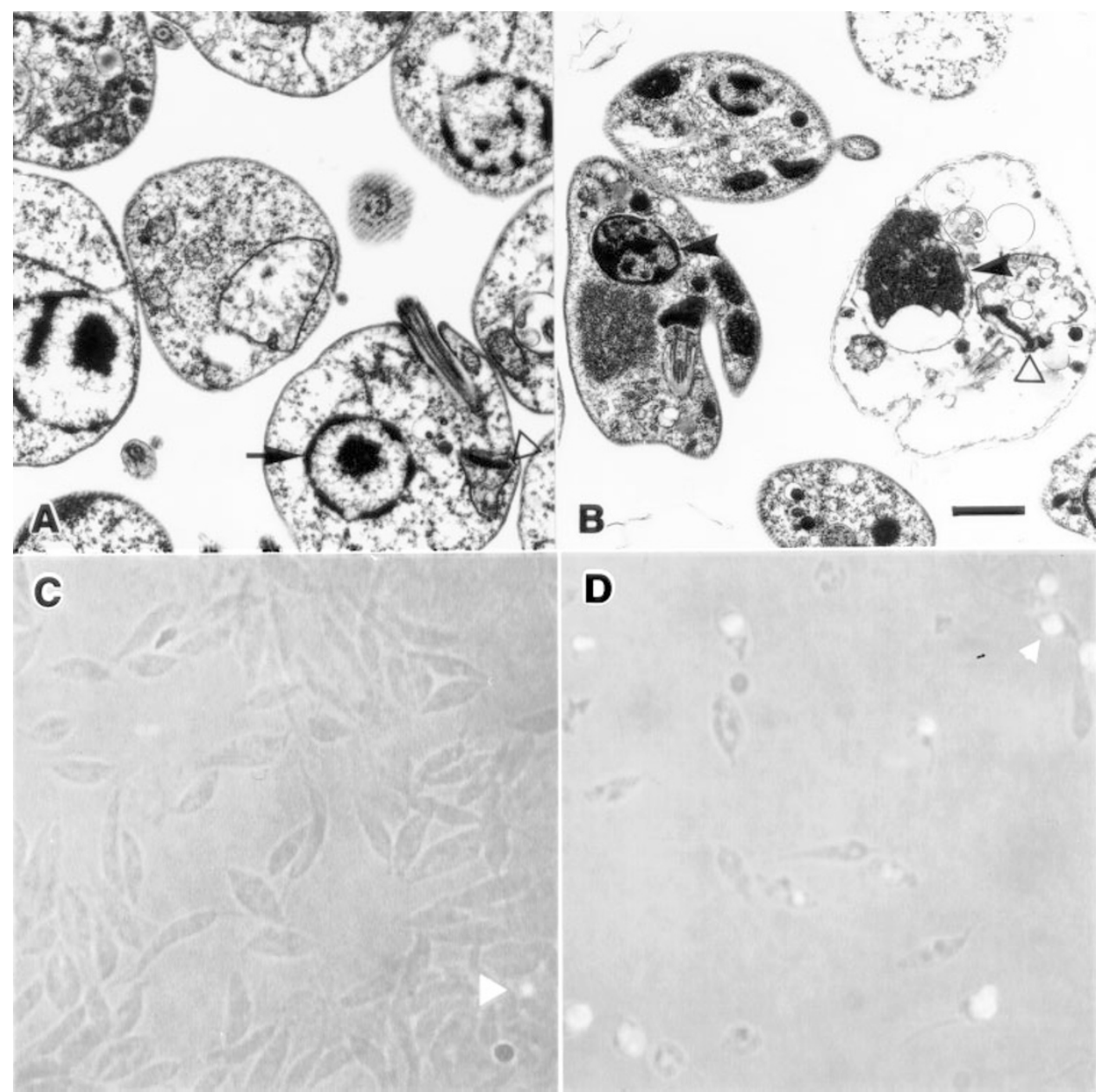

Figure 2 Transmission electron micrographs and TUNEL assay of promastigotes. Transmission electron micrographs of (A) late log (3 day old) and, (B) stationary (10 day old) L. donovani promastigotes. Arrows point to intact nuclei. Solid arrowheads point to condensed nuclei and empty arrowheads point to kinetoplasts. The bar in panel B indicates $1 \mu \mathrm{m}$. Merged phase contrast and fluorescent micrographs of the same field of late log (C), and stationary $L$. donovani promastigotes (D). Green nuclei resulting from the incorporation of FITC-labeled dUTP into nicked DNA are shown and are present predominantly in stationary phase cells. To the right of the white arrowhead is FITC-labeled nucleus in $\mathrm{C}$

\section{Induction of in vivo PPL-cleavage activity in Leishmania donovani}

In multicellular organisms, the effector phase of PCD involves the activation of a class of cysteine proteases called caspases. ${ }^{36}$ To assess whether a unicellular organism like Leishmania possesses similar effector molecules, we measured in vivo caspase-like activity in L. donovani promastigotes at various stages of growth in vitro. To that end, live cells were incubated with the cell permeable caspase-specific substrate PhiPhiLux (PPL) and the resulting intracellular fluorescent product was measured by flow cytometry. By day 4 , at the beginning of the stationary phase, no significant $(\sim 5 \%)$ PPL-cleavage activity was observed (Figure 5A, left panel). However, by day 7 up to $\sim 66 \%$ of the cells were PPL positive (Figure $5 \mathrm{~A}$, right panel), and remained constant thereafter (Figure 5B). This induction of activity coincided with the appearance of DNA ladder formation in promastigotes (Figure 1B). These results suggest that a PPL-cleavage activity is induced in stationary phase cultures of promastigotes.

We next investigated the sequence of events of PCD occurring at various stages of growth in promastigotes by measuring mitochondrial membrane potential, PPL-cleavage activity and plasma membrane integrity. To that end, fluorescence of cells treated with TMRE, PPL and propidium iodide (PI) was measured by FACS analysis. Each cell population exhibiting either low (M1) or high (M2) TMRE fluorescence was analyzed for PPL and PI fluorescence (Figure 6). The results show that in a culture having a high TMRE population (M2) representing $63.6 \%$ of cells, approximately $95 \%$ of these cells were double negative for $\mathrm{PI}$ fluorescence and PPL-cleavage activity (Figure 6B). In the subsequent 2 days, this M2 population dropped to $53.5 \%$ and $37.4 \%$ of total cells while remaining greater than $90 \%$ double negative (Figure $6 \mathrm{D}, \mathrm{F})$, suggesting that the high TMRE cells are not undergoing PCD. In contrast, the low TMRE (M1) 


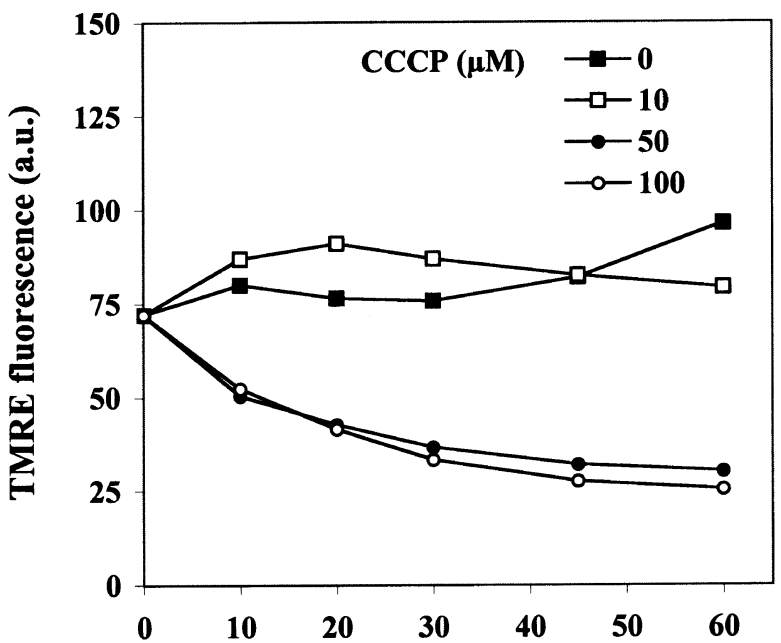

Time (min)

Figure 3 Effect of protonophore CCCP on the mitochondrial membrane potential as measured by fluorescence of TMRE. TMRE-loaded promastigotes at day 3 of culture (showing no hallmarks of PCD) were treated with different concentrations $(0-100 \mu \mathrm{M})$ of CCCP. The mean TMRE fluorescence was measured at different time points after addition of CCCP and is expressed as arbitrary units (a. u.)

population initially representing $36.7 \%$ of total cells at the first time point (Figure 6A), showed fewer double negative cells $(82.4 \%)$ and a corresponding increase in cells that were stained with $\mathrm{PI}$ and had PPL-cleavage activity (double positive, 7.8\%) (Figure 6A). Forty-eight hours later the low TMRE population rose to $46.7 \%$ of total cells and within that population $17.5 \%$ were double positive (Figure 6C). Seventy-two hours after the initial reading, the low TMRE population continued to increase $(62.7 \%$ of total cells) with a concomitant increase in double positive cells $(26.7 \%)$ (Figure 6E). At each of these time points in the low TMRE population, there were a number of $\mathrm{PI}$ positive cells lacking PPL-cleavage activity equal to the number of double positive cells. On the other hand, during this time course, only a limited number $(<5 \%)$ of low TMRE cells were PI negative and PPL-cleavage positive. These results show that during aging cells lose their mitochondrial membrane potential, which is followed by a simultaneous induction of plasma membrane permeability and PPL-cleavage activity. Taken together, from the above studies various features of a PCD can be demonstrated in Leishmania.

\section{Induction of PCD by anti-Leishmanial drugs in Leishmania donovani}

Human Leishmaniasis is initially treated with pentavalent antimony (SbV, Pentostam). The $10-25 \%$ of cases that are not cured by Pentostam are treated with amphotericin B. In both cases, these drugs are leishmanicidal. We explored whether the killing of Leishmania by these two drugs involved the PCD pathway as illustrated above. To that end, late log phase $L$. donovani promastigotes and axenic amastigotes were incubated for $10 \mathrm{~min}$ with increasing concentrations of amphotericin B and assayed for PPLcleavage activity as above. Results showed that PPLcleavage activity was induced in amphotericin B treated axenic amastigotes and promastigotes with an $\mathrm{IC}_{50}$ of $\sim 0.9 \mu \mathrm{g} / \mathrm{ml}$ and $\sim 0.4 \mu \mathrm{g} / \mathrm{ml}$ respectively (Figure 7). DNA ladder formation was observed in these cells after $2 \mathrm{~h}$ of treatment, and longer treatment with the drug $(>10 \mathrm{~h})$ resulted in complete degradation of DNA (data not shown). Pentostam treatment of promastigotes for $48 \mathrm{~h}$ did not induce significantly higher PPL-cleavage activity than the untreated cells, whereas treatment of axenic amastigotes with increasing concentration $(50-200 \mu \mathrm{g} / \mathrm{ml})$ resulted in a significant induction, $\sim 80 \%$ of cells were PPL-cleavage activity positive (data not shown).

\section{Decrease in mitochondrial membrane potential of Leishmania donovani promastigotes upon treatment with amphotericin B}

In our earlier experiments with the stationary phase cells (Figure 4), we observed a loss of mitochondrial membrane potential prior to induction of PPL-cleavage activity. We explored whether a similar change in mitochondrial membrane potential also occurred prior to the induction of PPL-cleavage activity by amphotericin B treatment. The TMRE and PPL-cleavage fluorescence was measured in late log phase promastigotes by FACS analysis at different times after treatment with $0.4 \mu \mathrm{g} / \mathrm{ml}$ of amphotericin B. Results show that a significant decrease (80\%) in mitochondrial membrane potential occurred within the first 2 min after treatment with amphotericin $B$ which remained low during the $30 \mathrm{~min}$ of treatment (Figure 8A). However, the appearance of PPL-positive cells was observed only after $10 \mathrm{~min}$ of amphotericin B treatment and the percentage of PPL positive cells continued to increase with longer treatment times (Figure 8A), suggesting that PPL-cleavage activity follows alteration in mitochondrial membrane potential.

We next investigated the sequence of events during PCD by measuring mitochondrial membrane potential, PPLcleavage activity and plasma membrane integrity in promastigotes at various times after $0.4 \mu \mathrm{g} / \mathrm{ml}$ amphotericin $\mathrm{B}$ treatment. To that end, fluorescence of cells treated with TMRE, PPL and propidium iodide (PI) was measured by FACS analysis (Figure 8B). Within $15 \mathrm{~min}$ of amphotericin $B$ treatment there was an $88 \%$ decrease in TMRE fluorescence compared to untreated cells (Figure 8B). However, there was only a small increase $(<4 \%)$ in the proportion of cells that exhibited both PPL-cleavage activity and PI staining. After $30 \mathrm{~min}$ of amphotericin B treatment a significant number of cells became either $\mathrm{PI}$ single positive (14.6\%) or PI and PPL double positive (13.4\%) with a concomitant decrease in double negative cells. These results again suggested that, similar to aging cells, amphotericin B treatment results in rapid decrease of mitochondrial membrane potential followed by a simultaneous induction of plasma membrane permeability and PPL-cleavage activity. 
D3
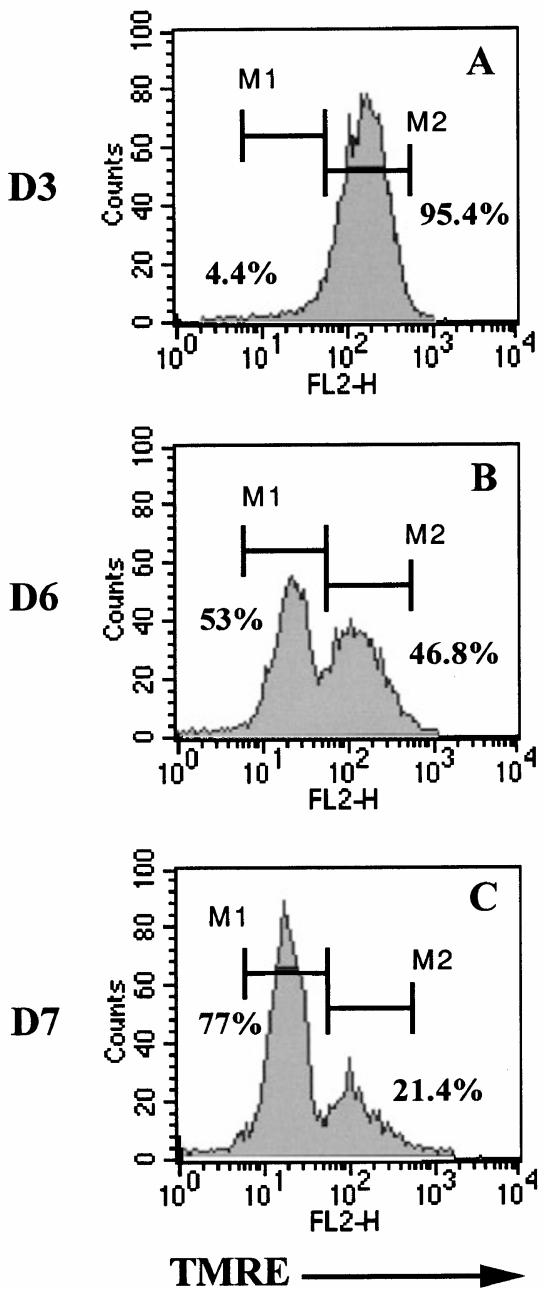
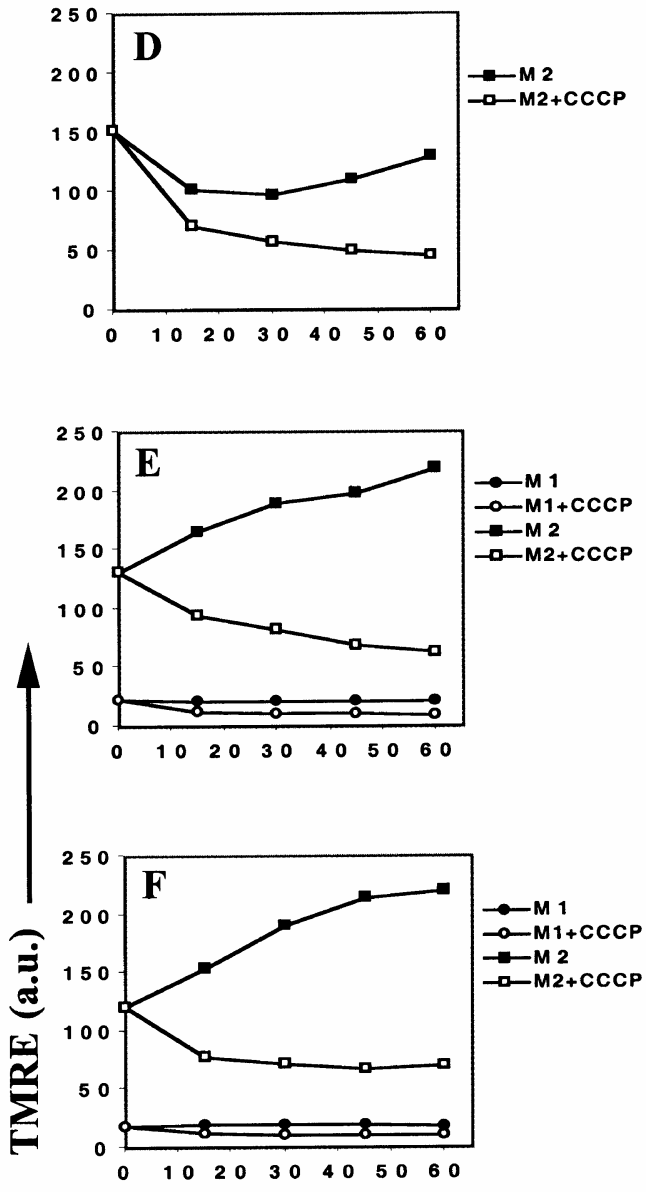

Time (min)

Figure 4 Change in the mitochondrial membrane potential of promastigotes during stationary phase in culture. (A, B, C) histograms showing fluorescence intensity of TMRE positive cells at days 3 (D3), 6 (D6), and 7 (D7) in culture. The high fluorescence intensity peaks are marked as M2, whereas the low fluorescence intensity peaks are marked as M1. (D, E, F) change in mitochondrial membrane potential of high (M2) and low (M1) TMRE fluorescent cells at different times after addition of $50 \mu \mathrm{M}$ CCCP

\section{Effect of various protease inhibitors on the PPL-cleavage activity, mitochondrial membrane potential and plasma membrane integrity in promastigotes}

To assess the nature of the protease activity that cleaved the PPL substrate, promastigotes were pre-incubated with various cell permeable caspase inhibitors (Z-VAD-FMK, ZDEVD-FMK, Boc-D-FMK) as well as with inhibitors of cathepsin (Mu-Phe-HPh-FMK) and Calpain (Calpeptin). After $60 \mathrm{~min}$ incubation with the inhibitor $(100 \mu \mathrm{M})$, parasites were induced with amphotericin $B$ and fluorescence of cells treated with TMRE, PPL and PI was measured by FACS analysis. Results showed that $21-34 \%$ inhibition of the amphotericin B inducible PPL-cleavage activity was observed in promastigotes treated with the three caspase inhibitors (Figure 9A) whereas no inhibition was observed in cells treated with either the cathepsin inhibitor or the calpain inhibitor or a control peptide (Z-FA-FMK) (data not shown). Similarly, when axenic amastigotes were treated with Z-VAD-FMK, only $\sim 15 \%$ of the PPL-cleavage activity was inhibited compared to untreated cells (data not shown). When the promastigotes were analyzed for PI staining, only cells treated with the caspase inhibitors showed significant reduction in percent of $\mathrm{PI}$ positive cells (15-21\%) (Figure 9B). The inhibitors did not prevent the loss of mitochondrial membrane potential $\left(\Delta \Psi_{\mathrm{m}}\right)$ as measured by TMRE fluorescence in promastigotes treated with caspase inhibitors suggesting that changes in $\Delta \Psi_{\mathrm{m}}$ occurs upstream of induction of PPL-cleavage activity. The inhibition of the PPLcleavage activity in promastigotes was observed only at low levels of induction by amphotericin B (when $\sim 25 \%$ of cells were PPL positive). These results suggest that of the total PPL-cleavage activity induced by amphotericin $B$ in $L$. donovani only $21-34 \%$ in promastigotes and $15 \%$ in axenic amastigotes may be comprised of caspase-like activity. Since other cysteine protease inhibitors did not inhibit the PPL- 
$\mathbf{A}$

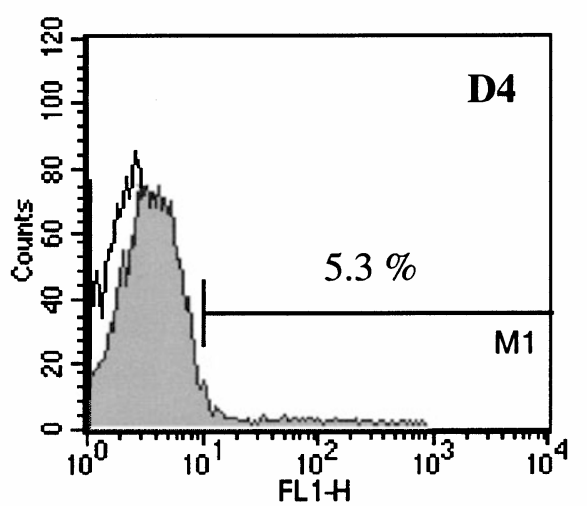

PPL fluorescence (a.u.)
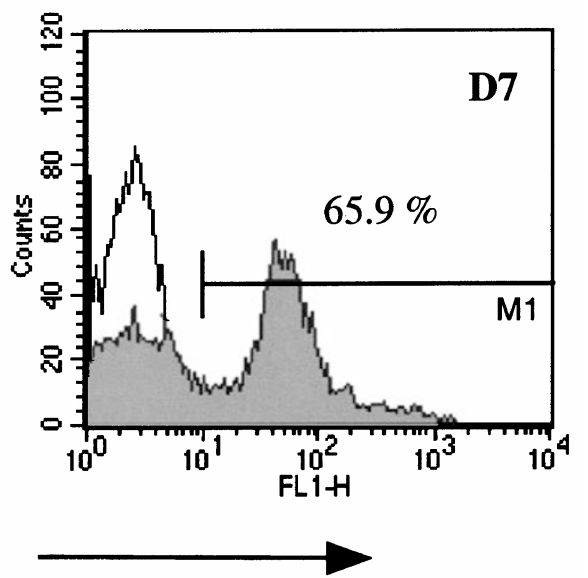

B

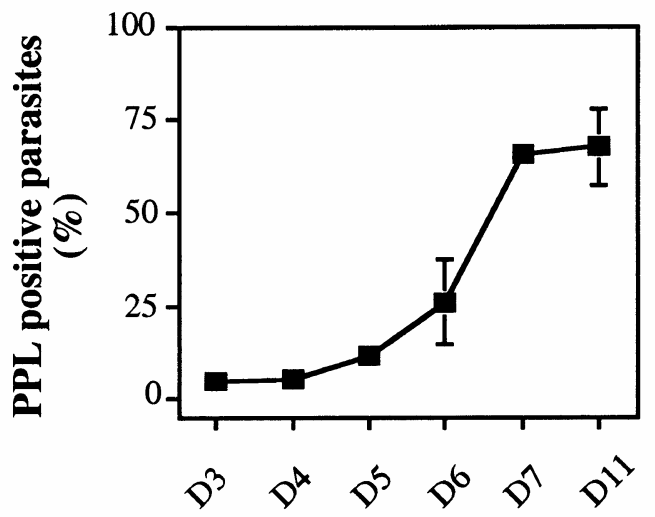

Days in culture

Figure 5 Analysis of PPL-cleavage activity in vivo in stationary phase promastigotes. (A) Fluorescence intensity of PPL loaded promastigote cells at day 4 and day 7 in culture (filled histograms). Open histograms represent basal cell fluorescence in the absence of PPL. Percent of PPL positive cells (M1 region) are indicated. (B) Increase of PPL positive promastigotes over time after initiation of the culture

cleavage activity, it is possible that there are either different proportions or different types of caspase-like activities induced by amphotericin B in promastigotes and axenic amastigotes of $L$. donovani.

\section{Discussion}

We have demonstrated that PCD exists in the unicellular protozoan parasite Leishmania donovani promastigotes and axenic amastigotes. The characteristic features of PCD observed in multicellular organisms such as nuclear condensation, nicked DNA in the nucleus, and DNA ladder formation were observed in promastigotes of $L$. donovani. In addition, we also observed induction of PPL-cleavage activity, which was partially, inhibited by a caspase inhibitors, in both axenic amastigotes and promastigotes upon initiation of PCD.
The induced PPL-cleavage activity was also not inhibited by inhibitors of other cysteine proteases such as cathepsin or calpain, which have been implicated to function in caspaseindependent manner to induce PCD. ${ }^{37,38}$ Therefore, suggesting that a certain fraction of total PPL-cleavage activity in Leishmania is caspase-like. However, the exact nature of the PPL-cleavage activity remains to be determined. The induction of PPL-cleavage activity, which coincided with increase in plasma membrane permeability, was observed after a drop in the mitochondrial membrane potential. The PCD was initiated when the parasites either reached stationary phase in culture or by exposure to anti-Leishmanial drugs.

PCD can be initiated by a number of different stimuli. However, the signaling mechanism by which these stimuli induce PCD is not clear. In the present study we tested the 

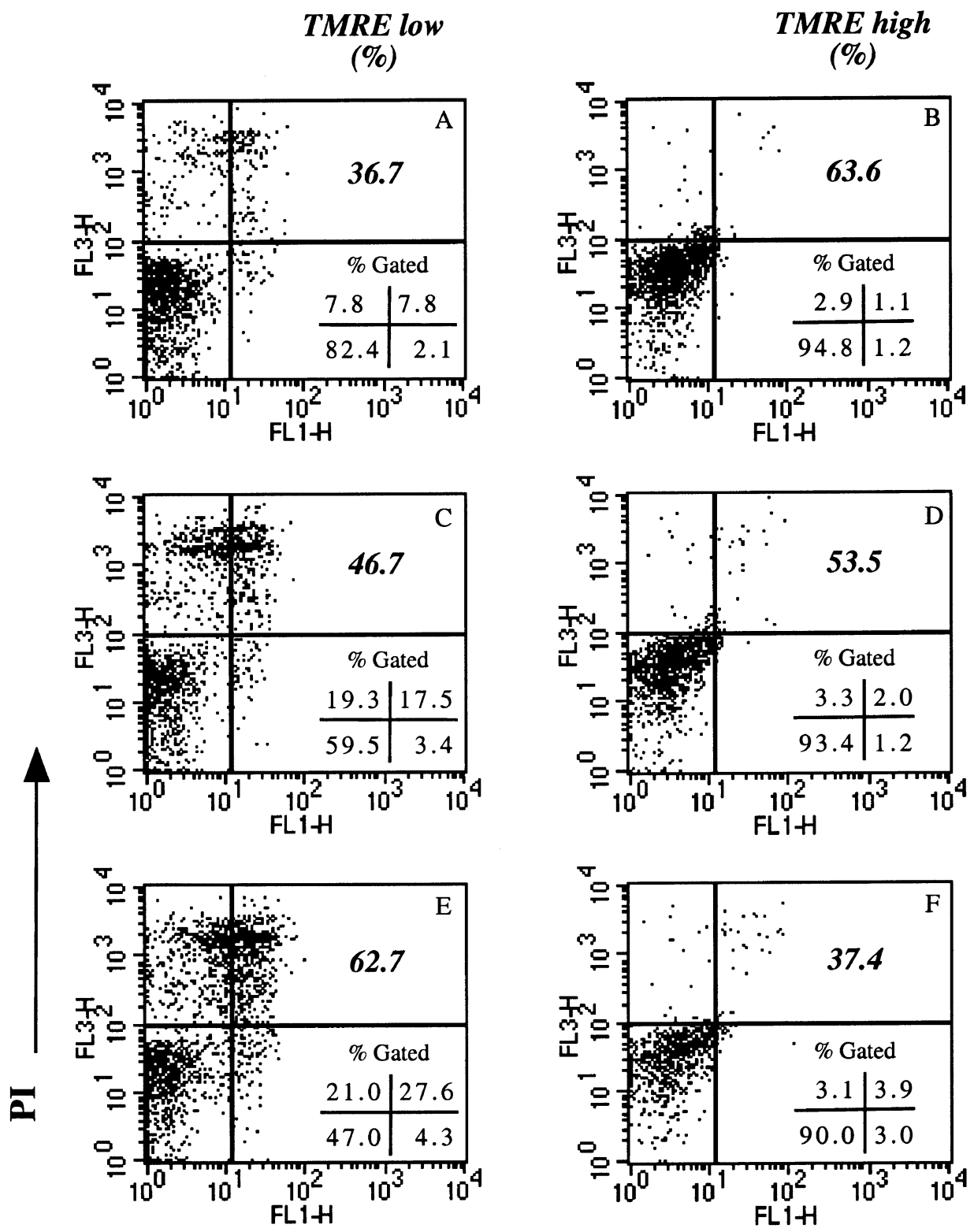

PPL

Figure 6 Analysis of mitochondrial membrane potential, PPL-cleavage activity and plasma membrane integrity in promastigotes during stationary phase in culture. Fluorescence of cells treated with TMRE, PPL and PI was measured by FACS analysis. (A, C, E) cells from different days in culture gated for low level of TMRE fluorescence, (B, D, F) cells gated for high level of TMRE fluorescence. Both populations were analyzed for PPL (FL-1) and PI (FL-3) fluorescence. The bold numbers represent the percentage of cells in each TMRE population. The percentage of cells gated for TMRE in each quadrant represent; lower left (double negative), upper left (PI, single positive), lower right (PPL, single positive), and upper right (PI, PPL double positive)

hypothesis whether Leishmania is amenable to death from various stimuli such as anti-Leishmanial drugs, which have been shown to kill intracellular parasites. ${ }^{39,40}$ We observed that the killing of Leishmania either by Pentostam or by amphotericin B is associated with markers of PCD. However, there were differences in the induction of PCD in promastigotes by Pentostam as compared to axenic amastigotes. Previously, similar differential sensitivity of $L$. donovani promastigotes to Pentostam has been observed. ${ }^{41}$ Thereby, suggesting that the two cell types of Leishmania respond differently to PCD signals, which could mean that there are either differences in the PCD machinery between these two cell types or differences in the sensitivities to the leishmanicidal activities of the drug. Interestingly, some of the features of PCD such as changes in the membrane integrity, increased electron density of the 


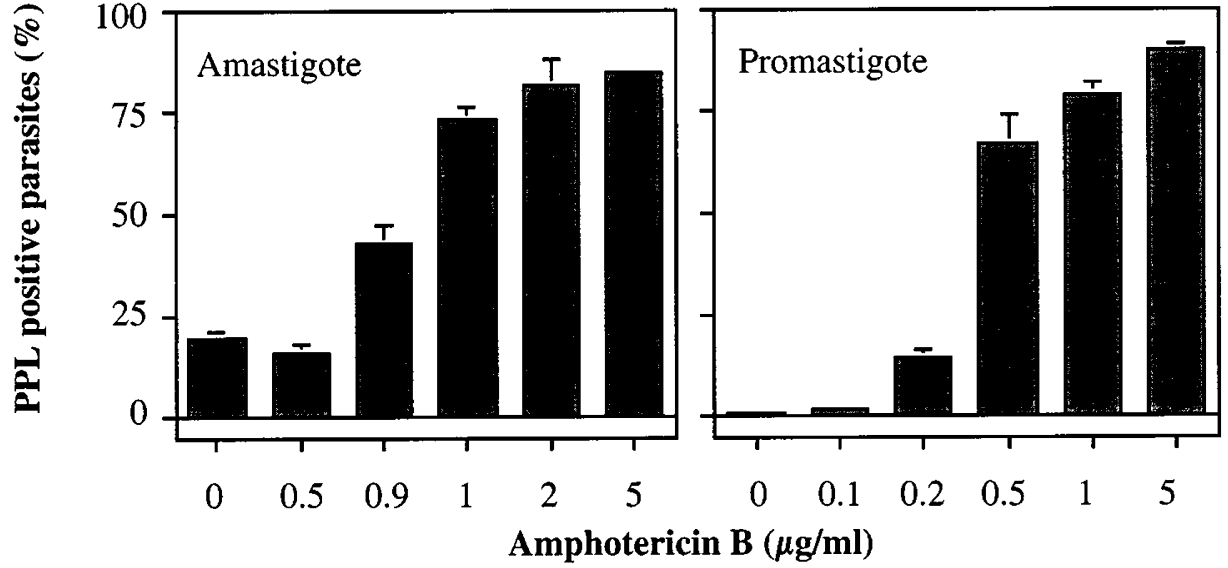

Figure 7 Induction of PPL-cleavage activity in axenic amastigotes and promastigotes by amphotericin B. Per cent of PPL positive cells in 3-day-old cultures of axenic amastigotes and promastigotes after $10 \mathrm{~min}$ of treatment with various concentrations of amphotericin $\mathrm{B}$. The concentration of amphotericin B $(\mu \mathrm{g} / \mathrm{ml})$ is indicated

cytoplasm, and nuclear condensation also have been observed in $L$. donovani inside macrophages isolated from patients as well as in L. tropica inside in vitro infected macrophages upon treatment with either Pentostam or amphotericin B. ${ }^{39,40}$ In addition, we also have demonstrated that PCD exists in both $L$. donovani and $L$. major that were freshly isolated from infected animals and grown in vitro as promastigotes for $2-5$ passages, as shown by the amphotericin B induced PPL-cleavage activity (data not shown). These observations suggest that PCD observed in laboratory adapted parasites, is also observed in parasites during infection.

Existence of PCD also has been described previously in Trypanosomatids such as $\mathrm{T}$. brucei rhodesiense, ${ }^{17} \mathrm{~T}$. cruzi, $^{13}$ and Leishmania amazonensis. ${ }^{18}$ In addition, PCD has been demonstrated in other unicellular organisms such as Tetrahymena ${ }^{42-44}$ and Dictyostelium discoideum. ${ }^{15}$ Further, bacteria and yeast, which do not undergo PCD and do not possess proteins homologous to any of the apoptotic regulators such as $\mathrm{Bcl}-2$ or $\mathrm{Bax}$, were shown to undergo cell death upon expression of proapototic proteins in either cell type. ${ }^{45-50}$ Similarly, a $S$. cerevisiae mutant that has a mutation in the cell division gene CDC48 showed typical markers of apoptosis. ${ }^{51,52}$ These studies therefore imply the presence of molecular machinery, which is able to perform the basic steps of apoptosis in lower eukaryotes and prokaryotes. The induction of PCD initiated in unicellular organisms such as Trypanosomatids, Tetrahymena, Dictyostelium by external signals or in bacteria and yeast by expression of proapoptotic proteins leads us to believe that the PCD pathway is present in unicellular as well as in multicellular organisms. However, the PCD pathways in the two types of organisms could be different. The definition of apoptosis has been used interchangeably with the term PCD. Recently, an alternative nonapoptotic form of PCD, parapoptosis, has been described, which is distinct from apoptosis by the criteria of morphology, biochemistry, and response to apoptosis inhibitors. ${ }^{19}$
Whether the PCD pathway observed in unicellular organisms is similar to parapoptosis remains to be seen. However, it has been postulated that PCD in Dictyostelium discoideum could resemble parapoptosis. ${ }^{15}$ Leishmania shares some of the features of PCD observed in multicellular organisms, including a change in mitochondrial membrane potential and induction of PPL-cleavage activity, which has some features of caspase-like activity, that has not been as yet reported in other unicellular organisms. However, there are also differences between PCD in Leishmania and that observed in multicellular organisms: (1) The PCD associated PPL-cleavage activity is only partially inhibited by several caspase inhibitors and is not inhibited by other cysteine protease inhibitors such as cathepsin or calpain, suggesting proteases other than or different from caspases may be involved; (2) The permeability of the plasma membrane to $\mathrm{PI}$ occurs simultaneously with activation of PPL-cleavage activity rather than following the activation of this activity; (3) There is no formation of apoptotic bodies. Thus the form of PCD in the unicellular parasite may be more similar to parapoptosis. Some of the differences may arise because the PCD in unicellular organisms is not adapted to lead to phagocytosis of the dead cells as in multicellular organisms. However, until the effector and regulatory molecules of PCD in Leishmania are identified and characterized, it is premature to conclusively define the type of cell death pathway in Leishmania.

Having established that PCD exists in Leishmania, the question arises with regards to the significance of this pathway in this parasite or in other unicellular organisms because each cell exists as an individual. This is in opposition to multicellular organism where controlling the number of certain cell types such as those in the immune, haemopoietic, and nervous systems is important for survival of the whole organism. Further, the failure to trigger $P C D$ in multicellular organisms may lead to uncontrolled growth resulting in various abnormalities such 

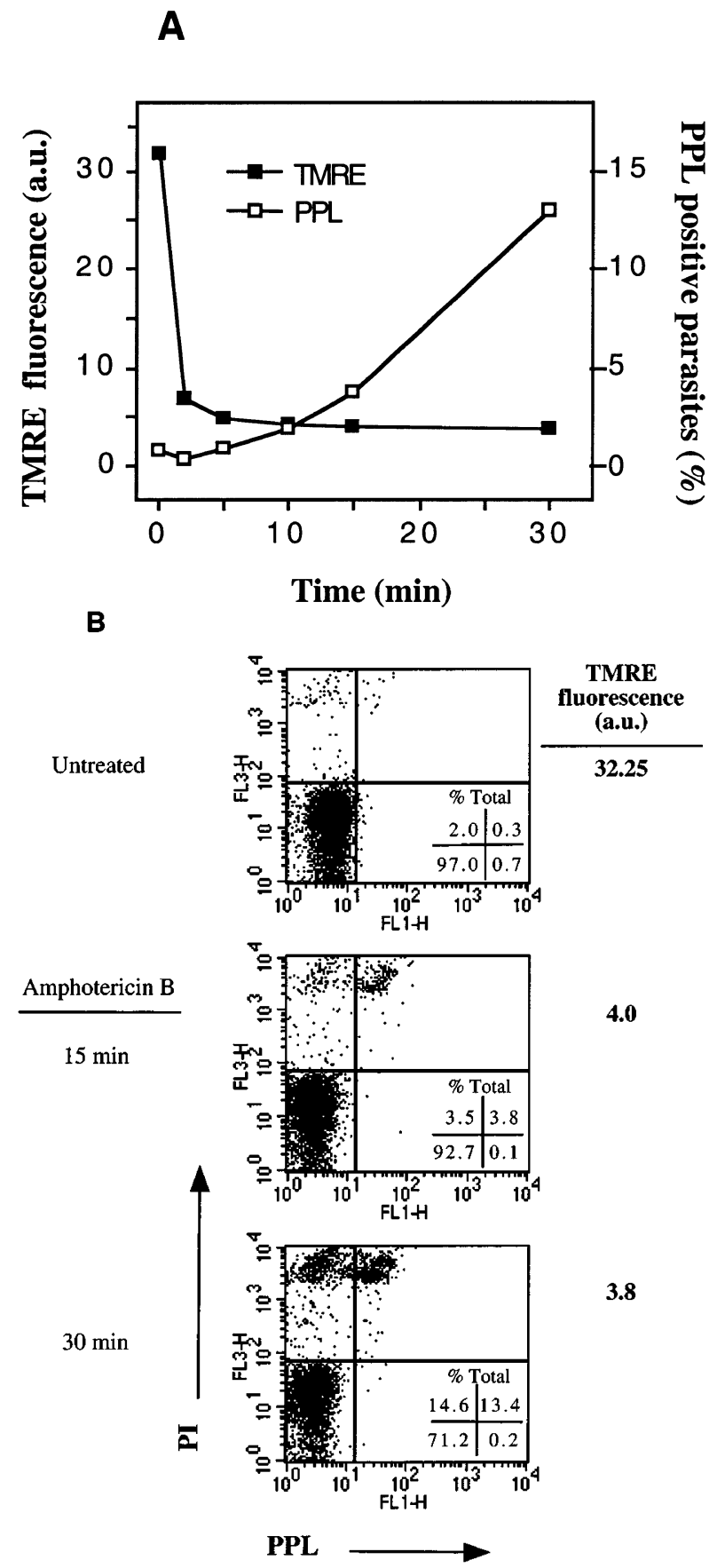

Figure 8 Analysis of mitochondrial membrane potential, PPL-cleavage activity and plasma membrane integrity in promastigotes treated with amphotericin B. (A) TMRE fluorescence and per cent of PPL positive promastigote cells at different times of treatment with amphotericin B $(0.4 \mu \mathrm{g} /$ $\mathrm{ml}$ ). (B) Fluorescence of cells loaded with TMRE, PPL, and PI was measured by FACS analysis in untreated and amphotericin B $(0.4 \mu \mathrm{g} / \mathrm{ml})$ treated promastigotes after 15 and $30 \mathrm{~min}$. Corresponding mean TMRE fluorescence of the cells is indicated in bold. The percentage of cells in each quadrant represent lower left (double negative), upper left (PI single positive), lower right (PPL single positive), and upper right (double positive)

as cancer, and autoimmune disease. One of the proposed functions of the PCD pathway in unicellular organisms is to control the cell population, as is the case in multicellular organisms. ${ }^{14,53-55}$ This has been substantiated previously by demonstration of PCD in dividing epimastigotes of $T$. cruzi undergoing differentiation to stationary phase trypomastigotes, ${ }^{16}$ in dying trypanosomes inside the tsetse fly mid gut, ${ }^{20}$ and after triggering of the differentiation process in Dictyostelium discoideum. ${ }^{15}$ In the present study we have observed that as soon as either promastigotes or axenic amastigotes enter stationary phase in culture there is a significant induction of PCD, and this induction can be delayed by transferring these parasites to fresh media (unpublished observations). The induction of PCD in stationary phase cultures in vitro could be due to the number of reasons such as differentiation; deprivation of nutrients essential for growth or due to increased cell density. Similarly it is conceivable that the PCD pathway could play a role in vivo in controlling the growth of Leishmania inside the sand fly gut, and could be triggered because of the limited resources in the sand fly gut. Alternatively, the PCD pathway could be a response to signals from the host such as growth factors or cytokines. ${ }^{56}$ In addition, PCD may be beneficial to the organism to maintain clonal characteristics by self-destruction of some cells and ensuring the propagation of other cells for the overall benefit of the parasite survival. ${ }^{18,57}$ For example, in the case of Leishmania promastigotes, which spend a significant time in the insect vector and differentiate into metacyclic forms before being transmitted to the mammalian host. ${ }^{58,59}$ However, it is not clear what happens to the rest of the undifferentiated procyclic parasite population during this time. Does PCD sort out the metacyclic form from the procyclic form and thus ensure the selection of the infectious form? Further studies using Leishmania isolated from the sandfly gut are essential to answer this question. In this regard, it is interesting to note that during transformation to infectious form the majority of $T$. brucei rhodesiense parasites fail to establish infection in the mid gut of tsetse fly and die with the characteristic apoptotic morphology. ${ }^{20}$

In conclusion, we have demonstrated that a type of PCD exists in Leishmania donovani, which is induced when the cells enter stationary phase in culture, and in response to anti-Leishmanial drugs. We also have evidence that PCD exists in freshly isolated parasites as well, thereby suggesting that it is not a phenomenon of in vitro culturing. Induction of PPL-cleavage activity in $L$. major leads us to believe that PCD is not restricted to $L$. donovani. Further, we argue that this is an adapted process that serves the long-term survival of some members of the population by eliminating unwanted individuals. The process is dependent on expression of cellular proteins such as the ones responsible for PPL-cleavage activity. However, it remains to be determined whether similar induction of PCD takes place in Leishmania inside the insect gut or vertebrate macrophages. In addition, to understand the mechanism of Leishmania PCD pathway, both regulatory and effector molecules involved in this pathway have to be established in Leishmania. In that regard, we have shown in this study the protease activity induced in parallel with nuclear changes is comprised partly by the caspase-like proteases. 
A

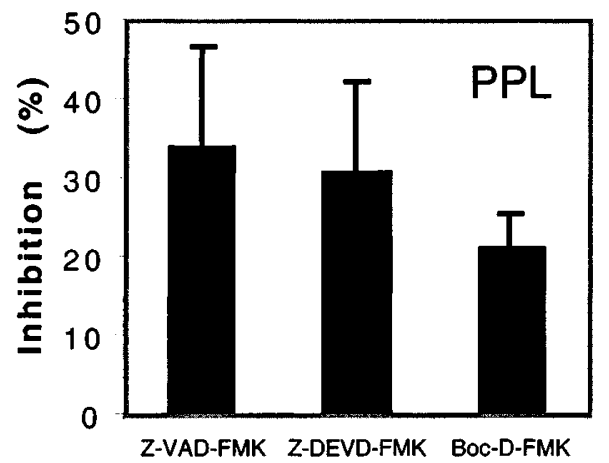

B

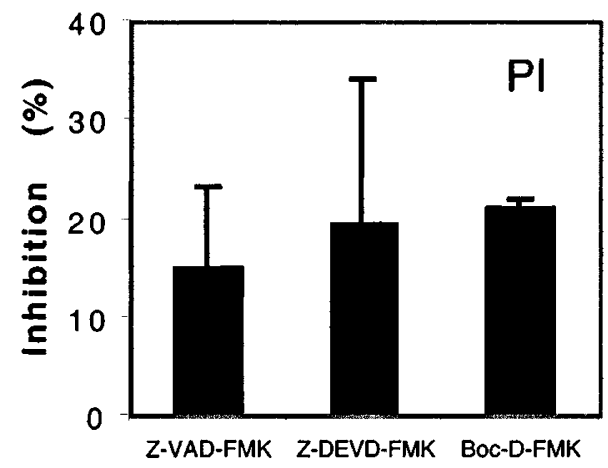

Figure 9 Inhibition of PPL-cleavage activity and plasma membrane integrity by different caspase inhibitors in promastigotes treated with amphotericin B. (A) Per cent of inhibition of PPL-cleavage activity in promastigotes treated with amphotericin $\mathrm{B}$, after incubation with different caspase inhibitors (100 $\mu \mathrm{M}$ ). Mean with standard error bar results from three independent experiments is shown. (B) Per cent of inhibition of PI positive cells in promastigotes treated with amphotericin B after incubation with different caspase inhibitors $(100 \mu \mathrm{M})$. Mean with standard error bar results from three independent experiments is shown

Further studies are needed to characterize these and other molecules involved in PCD in Leishmania. A detailed understanding of the mechanism of PCD will be helpful in devising therapeutic strategies to design drugs that can induce preferential killing of Leishmania.

\section{Materials and Methods}

\section{In vitro culture of parasites}

A cloned line of $L$. donovani (WHO designation: MHOM/SD/62/1S$\mathrm{C1}_{2 \mathrm{D}}$ ) was used in all experiments. ${ }^{60}$ Promastigotes and axenic amastigotes were grown, and harvested as described previously. ${ }^{60} \mathrm{~L}$. donovani [WHO designation MHOM/SD/00/IS-2D] and L. major [WHO designation $\mathrm{MHOM} / \mathrm{IL} / 80 /$ Friedlin] parasites, freshly isolated from infected hamster and BALB/C mice, respectively, ${ }^{61}$ were kindly provided by Dr. David Sacks (NIH, Bethesda, MD, USA) and were maintained as promastigote cultures as above for less than five passages.

\section{Electron microscopy}

Cells were fixed with $2 \%$ glutaraldehyde- $2 \%$ paraformaldehyde in $0.1 \mathrm{M}$ sodium cacodylate buffer, $\mathrm{pH} 7.3$, for $3 \mathrm{~h}$ and stored in PBS at $4{ }^{\circ} \mathrm{C}$. Cells were post-fixed for $1 \mathrm{~h}$ with $2 \%$ osmium tetraoxide, dehydrated with graded alcohols, and embedded in epoxy resin. Thin sections were stained with uranyl acetate and lead citrate and examined with a Zeiss EM 912 Omega electron microscope.

\section{TUNEL assay}

L. donovani promastigote cells were grown for different lengths of time in chamber slides, washed with PBS, fixed in $75 \%$ methanol $/ 2.5 \%$ acetic acid, rinsed twice with PBS, layered with TUNEL reaction mixture (Boehringer Mannheim) containing FITC-labeled dUTP and terminal deoxynucleotidyl transferase, and incubated for $1 \mathrm{~h}$ at $37^{\circ} \mathrm{C}$ in a moist chamber. Cells were visualized on a fluorescent microscope, and images captured with a digital video camera and processed with Adobe PhotoShop software.

\section{DNA gel analysis}

Total genomic DNA was isolated from parasites as described in the $G$ NOME DNA kit protocol (Bio-101, Inc). Usually $5 \times 10^{8}$ to $1 \times 10^{9}$ cells were used for extraction of DNA. Approximately $10 \mu \mathrm{g}$ of genomic DNA was run on $1 \%$ agarose gels in $1 \%$ Tris-Acetate-EDTA (TAE) buffer. $^{60}$ The gels were stained with ethidium bromide and visualized under UV light. DNA ladder data presented are representative of at least three independent experiments.

\section{FACS analysis of PPL-cleavage activity in live Leishmania}

A PhiPhiLux G1D2 (PPL, Calbiochem, La Jolla, CA, USA) substrate was used to measure caspase-like activity by flow cytometry in living cells. This peptide substrate contains a caspase-3 specific GDEVDGI sequence with the cleavage site located between $D$ and $G$ and is conjugated to two fluorophores (G1D2). The quenched fluorophores fluoresce upon cleavage of the peptide. ${ }^{33} 2 \times 10^{6}$ cells were resuspended into $25 \mu \mathrm{l}$ medium (RPMI 1640, 10\% FBS, $20 \mathrm{mM}$ HEPES pH 7), incubated with additional $25 \mu \mathrm{l} \mathrm{PPL}$ for $15-30 \mathrm{~min}$ at $37^{\circ} \mathrm{C}$, washed and resuspended into $500 \mu \mathrm{l}$ cytometry dilution buffer (Caspase-3 intracellular activity assay kit I; Calbiochem). The cells were dispersed by several passings through a 26-gauge needle and analyzed using a FACScan flow cytometer (Becton Dickinson). FL1-H fluorescence was recorded on 10000 events gated according to forward and side scatter and analyzed using CellQuest software. Data are expressed as per cent of PPL positive cells and are representative of three independent experiments. Induction of PCD by amphotericin B (Sigma) or pentavalent antimony (SbV, Pentostam, The Wellcome Foundation Ltd., London, UK) was done by incubating 3-day-old (late log phase) parasite cultures for the indicated periods of time with different concentrations of inducer prior to processing cells for PPLcleavage activity as above.

\section{Measurement of mitochondrial membrane potential $\left(\Delta \Psi_{\mathrm{m}}\right)$ in live Leishmania promastigotes}

Tetramethylrhodamine ethylester perchlorate (TMRE, Molecular Probes, Inc., Eugene, OR, USA) is a cationic lipophilic dye that accumulates in the negatively charged mitochondrial matrix according to the Nernst equation potential. ${ }^{33}$ A stock of TMRE was prepared at a 
concentration of $4 \mathrm{mg} / \mathrm{ml}$ in DMSO and stored at $-20^{\circ} \mathrm{C}$. For estimation of $\left(\Delta \Psi_{\mathrm{m}}\right), L$. donovani promastigotes were washed once in PBS and resuspended at $2 \times 10^{6}$ cells $/ \mathrm{ml}$ in PBS containing $100 \mathrm{nM}$ TMRE. Cells were dispersed by several passings through a 26-gauge needle, incubated for $15 \mathrm{~min}$ at room temperature and analyzed by flow cytometry on the FL2-H channel. Baseline TMRE was recorded and expressed as mean fluorescence in arbitrary units (a.u.). Subsequently, carbonyl cyanide m-chlorophenylhydrazone (CCCP, Sigma) was added to the cells $(10-200 \mu \mathrm{M}$ final concentration) and TMRE fluorescence was measured at various times up to $60 \mathrm{~min}$. CCCP depolarizes mitochondria by abolishing the proton gradient across the inner mitochondrial membrane. ${ }^{62,63}$ In some experiments, L. donovani promastigotes were first incubated with PPL for $15 \mathrm{~min}$ as above and subsequently resuspended in PBS containing $100 \mathrm{nM}$ TMRE and $4 \mu \mathrm{g} / \mathrm{ml}$ propidium iodide (PI, Biosciences, Inc., La Jolla, CA, USA). After $15 \mathrm{~min}$ incubation at room temperature, cells were analyzed by flow cytometry as above. PI fluorescence was recorded on the FL3-H channel.

\section{Inhibition of the PPL-cleavage activity in live Leishmania}

For inhibition studies, the following protease inhibitors were used: ZVal-Ala-Asp (OMe)- $\mathrm{CH}_{2} \mathrm{~F}$ (Z-VAD-FMK, Alexis Biochemicals, San Diego, CA, USA); Z-Asp (OMe)-Glu (OMe)-Val-Asp (OMe)- $\mathrm{CH}_{2} \mathrm{~F}$ (ZDEVD-FMK, Calbiochem); Boc-Asp (OMe)- $\mathrm{CH}_{2} \mathrm{~F}$ (Boc-D-FMK, Calbiochem); Z-Phe-Ala- $\mathrm{CH}_{2} \mathrm{~F}$ (Z-FA-FMK, Enzyme Systems Products, Livermore, CA, USA); Mu-Phe-HPh- $\mathrm{CH}_{2} \mathrm{~F}$ (Mu-Phe-HPh-FMK, Enzyme Systems Products); Calpeptin (Calbiochem). $2.4 \times 10^{7}$ promastigotes from a 3-day-old culture were incubated at $26^{\circ} \mathrm{C}$ for $60 \mathrm{~min}$ in $400 \mu \mathrm{l}$ of culture medium containing either $100 \mu \mathrm{M}$ of each protease inhibitors described above or equivalent amount of DMSO and further treated for an additional $10 \mathrm{~min}$ with different concentrations of amphotericin B to induce PCD. An aliquot of $2 \times 10^{6}$ cells was subsequently washed in $1 \mathrm{ml}$ RPMI 1640 (Gibco) and resuspended in $25 \mu$ l medium containing either $200 \mu \mathrm{M}$ of the corresponding protease inhibitor or equivalent amount of DMSO, and an equal volume $(25 \mu \mathrm{l})$ of PPL substrate. After 15 min incubation at $37^{\circ} \mathrm{C}$, cells were washed in $1 \mathrm{ml}$ PBS, resuspended in PBS containing $100 \mathrm{nM}$ TMRE and $4 \mu \mathrm{g} /$ $\mathrm{ml}$ propidium iodide and analyzed by flow cytometry as above.

\section{Acknowledgements}

Authors would like to thank Drs. Dwyer and Sacks (NIAID, NIH) for critical reading of the manuscript. We thank Drs. Navdeep Chandel and Gerry Melino for providing helpful suggestions in performing mitochondrial membrane potential experiments. We also thank Dr. Sacks for providing the two strains of Leishmania that were freshly isolated from infected animals.

\section{References}

1. Killick KR (1979) Biology of Leishmania in phlebotomine sand flies. In: Lumsden Whrae DA (ed) Biology of kinetoplastida. Vol. I. Academic Press: New York $395-449$

2. Alexander J and Vickerman K (1975) Fusion of host cell secondary lysosomes with parasitophorous vacoules of Leishmania mexicana-infected macrophages. J. Protozool. 22: 502-508

3. Chang K-P and DwyerDM (1976) Multiplication of a human parasite (Leishmania donovani) in phagolysosomes of hamster macrophages in vitro. Science 193: $678-680$
4. Molyneux DH (1983) Host-parasite relationships of trypanosomatidalin vectors. In current topics in Pathogen-Vector-Host Research. (K.F. Harris, Ed.) Vol 1, pp117-148

5. Alexander J and Russell DG (1992) The interaction of Leishmania species with macrophages. Adv. Parasitol. 32: 175-254

6. Vaux DL, Haecker G and Strasser A (1994) An evolutionary perspective on apoptosis. Cell 76: $777-779$

7. Evan G (1994) Why we live and why we die. Chem. Biol. 1: 137-141

8. Roulston A, Marcellus RC and Branton PE (1999) Viruses and apoptosis. Annu. Rev. Microbiol. 53: 577-628

9. Duncan R, Muller J, Lee N, Esmaili A and Nakhasi HL (1999) Rubella virusinduced apoptosis varies among cell lines and is modulated by $\mathrm{Bcl}-\mathrm{XL}$ and caspase inhibitors. Virology 255: $117-128$

10. Duncan R, Esmaili A, Law LM, Bertholet S, Hough C, Hobman TC and Nakhasi $\mathrm{HL}$ (2000) Rubella virus capsid protein induces apoptosis in transfected RK13 cells. Virology 275: $20-29$

11. Raff MC (1992) Social controls on cell survival and cell death. Nature 356: $397-$ 400

12. Reed JC (1994) Bcl-2 and the regulation of programmed cell death. J. Cell. Biol. 124: $1-6$

13. Ameisen JC (1996) The origin of programmed cell death. Science 272: $1278-$ 1279

14. Welburn SC, Barcinski MA and Williams GT (1997) Programmed cell death in trypanosomatids. Parasitol. Today 13: 22-26

15. Cornillon S, Foa C, Davoust J, Buonavista N, Gross JD and Golstein P (1994) Programmed cell death in Dictyostelium. J. Cell. Sci. 107: 2691-2704

16. Ameisen JC, Idziorek T, Billaut-Mulot O, Loyens M, Tissier J-P, Potentier A and Quaissi A (1995) Apoptosis in a unicellular eukaryote (trypanosoma cruzi): implications for the evolutionary origin and role of programmed cell death in the control of cell proliferation, differentiation and survival. Cell Death Differ. 2: 285300

17. Welburn SC, Dale C, Ellis D, Beecroft R and Pearson TW (1996) Apoptosis in procyclic $T$. B. rhodesiense in vitro. Cell Death Differ. 3: 229-236

18. Moreira ME, Del Portillo HA, Milder RV, Balanco JM and Barcinski MA (1996) Heat shock induction of apoptosis in promastigotes of the unicellular organism Leishmania (Leishmania) amazonensis. J. Cell. Physiol. 167: 305-313

19. Sperandio S, de Belle I and Bredesen DE (2000) An alternative, nonapoptotic form of programmed cell death. Proc. Natl. Acad. Sci. USA 97: 14376-14381

20. Welburn SC, Maudlin I and Ellis DS (1989) Rate of trypanosome killing by lectins in midguts of different species and strains of Glossina. Med. Vet. Entomol. 3: 77-82

21. Ankarcrona M, Dypbukt JM, Bonfoco E, Zhivotovsky B, Orrenius S, Lipton SA and Nicotera P (1995) Glutamate-induced neuronal death: a succession of necrosis or apoptosis depending on mitochondrial function. Neuron. 15: $961-$ 973

22. Zamzami N, Marchetti $P$, Castedo M, Hirsch T, Susin SA, Masse B and Kroemer $\mathrm{G}$ (1996) Inhibitors of permeability transition interfere with the disruption of the mitochondrial transmembrane potential during apoptosis. FEBS Lett. 384: 5357

23. HenkartPA and Grinstein S (1996) Apoptosis: mitochondria resurrected? J. Exp. Med. 183: 1293-1295

24. Boise LH and Thompson CB (1997) Bcl-x(L) can inhibit apoptosis in cells that have undergone Fas-induced protease activation. Proc. Natl. Acad. Sci. USA 94: $3759-3764$

25. Wadia JS, Chalmers-Redman RM, JuWJ, Carlile GW, Phillips JL, Fraser AD and Tatton WG (1998) Mitochondrial membrane potential and nuclear changes in apoptosis caused by serum and nerve growth factor withdrawal: time course and modification by (-)-deprenyl. J. Neurosci. 18: 932-947

26. Heiskanen KM, Bhat MB, Wang HW, Ma J and Nieminen AL (1999) Mitochondrial depolarization accompanies cytochrome crelease during apoptosis in PC6 cells. J. Biol. Chem. 274: 5654-5658

27. Kluck RM, Bossy-Wetzel E, Green DR and Newmeyer DD (1997) The release of cytochrome $\mathrm{c}$ from mitochondria: a primary site for $\mathrm{Bcl}-2$ regulation of apoptosis. Science 275: $1132-1136$

28. Vander Heiden MG, Chandel NS, Williamson EK, Schumacker PT and Thompson CB (1997) Bcl-xL regulates the membrane potential and volume homeostasis of mitochondria. Cell 91:627-637

29. Yang J, Liu X, Bhalla K, Kim CN, Ibrado AM, Cai J, Peng TI, Jones DP and WangX (1997) Prevention of apoptosis by Bcl-2: release of cytochrome c from mitochondria blocked. Science 275: 1129-1132 
30. Bossy-WetzelE, NewmeyerDD and Green DR (1998) Mitochondrial cytochrome c release in apoptosis occurs upstream of DEVD-specific caspase activation and independently of mitochondrial transmembrane depolarization. EMBO J. 17: $37-49$

31. Yoshida H, Kong YY, Yoshida R, Elia AJ, Hakem A, Hakem R, Penninger JM and Mak TW (1998) Apaf1 is required for mitochondrial pathways of apoptosis and brain development. Cell 94: 739-750

32. Krohn AJ, Wahlbrink T and Prehn JH (1999) Mitochondrial depolarization is not required for neuronal apoptosis. J. Neurosci. 19: 7394-7404

33. Ehrenberg B, Montana V, Wei MD, Wuskell JP and Loew LM (1988) Membrane potential can be determined in individual cells from the nernstian distribution of cationic dyes. Biophys. J. 53: 785-794

34. Gunter TE and Pfeiffer DR (1990) Mechanisms by which mitochondria transport calcium. Am. J. Physiol. 258: C755-C786

35. Prehn JH, Bindokas VP, Marcuccilli CJ, Krajewski S, Reed JC and Miller RJ (1994) Regulation of neuronal Bcl2 protein expression and calcium homeostasis by transforming growth factor type beta confers wide-ranging protection on rat hippocampal neurons. Proc. Natl. Acad. Sci. USA 91: 12599-12603

36. Nicholson DW and Thornberry NA (1997) Caspases: killer proteases. Trends Biochem. Sci. 22: 299-306

37. Schotte P, Declercq W, Van Huffel S, Vandenabeele P and Beyaert R (1999) Non-specific effects of methyl ketone peptide inhibitors of caspases. FEBS Lett. 442: $117-121$

38. Wolf BB, Goldstein JC, Stennicke HR, Beere H, Amarante-Mendes GP, Salvesen GS and Green DR (1999) Calpain functions in a caspase-independent manner to promote apoptosis- like events during platelet activation. Blood 94: 1683-1692

39. Chulay JD, Fawcett DW and Chunge CN (1985) Electron microscopy of Leishmania donovani in splenic aspirates from patients with visceral leishmaniasis during treatment with sodium stibogluconate. Ann. Trop. Med. Parasitol. 79: 417-429

40. Langreth SG, Berman JD, Riordan GP and Lee LS (1983) Fine-structural alterations in Leishmania tropica within human macrophages exposed to antileishmanial drugs in vitro. J. Protozool. 30: 555-561

41. Ephros M, Bitnun A, Shaked P, Waldman E and Zilberstein D (1999) Stagespecific activity of pentavalent antimony against Leishmania donovani axenic amastigotes. Antimicrob. Agents Chemother. 43: 278-282

42. Davis MC, Ward JG, Herrick G and Allis CD (1992) Programmed nuclear death: apoptotic-like degradation of specific nuclei in conjugating Tetrahymena. Dev. Biol. 154: 419-432

43. Christensen ST, Wheatley DN, Rasmussen MI and Rasmussen L (1995) Mechanisms controlling death, survival and proliferation in a model unicellular eukaryote Tetrahymena thermophila. Cell Death Differ. 2: 301-308

44. Christensen ST, Leick V, Rasmussen L and Wheatley DN (1998) Signaling in unicellular eukaryotes. Int. Rev. Cytol. 177: 181-253

45. Asoh S, Nishimaki K, Nanbu-Wakao R and Ohta S (1998) A trace amount of the human pro-apoptotic factor Bax induces bacterial death accompanied by damage of DNA. J. Biol. Chem. 273: 11384-11391

46. Nanbu-Wakao R, Asoh S, Nishimaki K, Tanaka R and Ohta S (2000) Bacterial cell death induced by human pro-apoptotic Bax is blocked by an RNase E mutant that functions in an anti-oxidant pathway. Genes. Cells 5: 155-167
47. Sato T, Hanada M, Bodrug S, Irie S, Iwama N, Boise LH, Thompson CB, Golemis E, Fong L, Wang HG, Reed JC (1994) Interactions among members of the Bcl-2 protein family analyzed with a yeast two-hybrid system. Proc. Natl. Acad. Sci. USA 91: 9238-9242

48. Greenhalf W, Stephan C and Chaudhuri B (1996) Role of mitochondria and Cterminal membrane anchor of $\mathrm{Bcl}-2$ in Bax induced growth arrest and mortality in Saccharomyces cerevisiae. FEBS Lett. 380: 169-175

49. Jurgensmeier JM, Krajewski S, Armstrong RC, Wilson GM, Oltersdorf T, Fritz LC, Reed JC and Ottilie S (1997) Bax-and Bak-induced cell death in the fission yeast Schizosaccharomyces pombe. Mol. Biol. Cell 8: 325-339

50. Jurgensmeier JM, Xie Z, Deveraux Q, Ellerby L, Bredesen D and Reed JC (1998) Bax directly induces release of cytochrome $\mathrm{c}$ from isolated mitochondria. Proc. Natl. Acad. Sci. USA 95: 4997-5002

51. Madeo F, Frohlich E and Frohlich KU (1997) A yeast mutant showing diagnostic markers of early and late apoptosis. J. Cell. Biol. 139: 729-734

52. Madeo F, Frohlich E, Ligr M, Grey M, Sigrist SJ, Wolf DH and Frohlich KU (1999) Oxygen stress: a regulator of apoptosis in yeast. J. Cell. Biol. 145: 757-767

53. Lymbery AJ, Hobbs RP and Thompson RC (1997) Building bridges and controlling parasites. Int. J. Parasitol. 27: 1119-1120

54. Anderson RM (1998) Complex dynamic behaviours in the interaction between parasite population and the host's immune system. Int. J. Parasitol. 28:551-566

55. Barcinski MA and DosReis GA (1999) Apoptosis in parasites and parasiteinduced apoptosis in the host immune system: a new approach to parasitic diseases. Braz. J. Med. Biol. Res. 32: 395-401

56. Barcinski MA, Charlab R, Soares LR, Moreira ME, Zalis MG and Magalhaes AM (1988) The role of hematopoietic growth factors in the fate of an infection with Leishmania mexicana amazonensis: an attempt at a unifying hypothesis. Mem. Inst. Oswaldo Cruz. 83 Suppl 1: 411-413

57. Vickerman K (1985) Developmental cycles and biology of pathogenic Trypanosomes. Br. Med. Bull. 41: 105-114

58. Sacks DL and Perkins PV (1984) Identification of an infective stage of Leishmania promastigotes. Science 223: 1417-1419

59. Sacks DL (1989) Metacyclogenesis in Leishmania promastigotes. Exp. Parasitol. 69: 100-103

60. Joshi M, Dwyer DM and Nakhasi HL (1993) Cloning and characterization of differentially expressed genes from in vitro-grown 'amastigotes' of Leishmania donovani. Mol. Biochem. Parasitol. 58: 345-354

61. Sacks DL, Pimenta PF, McConville MJ, Schneider P and Turco SJ (1995) Stagespecific binding of Leishmania donovanito the sand fly vector midgut is regulated by conformational changes in the abundant surface lipophosphoglycan. J. Exp. Med. 181: 685-697

62. Chandel NS, Budinger GR, Choe SH and Schumacker PT (1997) Cellular respiration during hypoxia. Role of cytochrome oxidase as the oxygen sensor in hepatocytes. J. Biol. Chem. 272: 18808-18816

63. Scaduto Jr RC and Grotyohann LW (1999) Measurement of mitochondrial membrane potential using fluorescent rhodamine derivatives. Biophys. J. 76: $469-477$ 